\title{
Extraction and Recognition Methods of Vehicle Driving Tendency Feature Based on Driver- vehicle-environment Dynamic Data under Car Following
}

\author{
Xiaoyuan Wang* \\ Institute of Intelligent Transportation, Shandong University of Technology \\ Zibo255091, Shandong province, P. R. China \\ Jinglei Zhang \\ School of Transportation and Vehicle Engineering, Shandong University of Technology \\ Zibo255091, Shandong province, P. R. China \\ Received 30 July 2011 \\ Accepted 25 November 2011
}

\begin{abstract}
Driving tendency is the comprehensive embodiment of driver's physiological and psychological characteristics. It reflects driver's psychological condition during the process of driving. Identification of the driving tendency has great significance to researching of the driver assistant system, especially the active security warning system. In this paper, data from simulative driving and real driving experiment of different drivers (risk-taking, cautious and conservative type, etc) under the state of car-following flow are obtained through questionnaires on psychological test. The feature eigenvectors with good ability to classify the type of driving tendency is extracted based on rough set theory. Dynamic recognition method of driving tendency is put forward with model calibration and verification making use of real data. The results of verification are compared with the results of the questionnaires. It is shown that the pattern recognition model is feasible, and can realize real-time recognition of the driver tendency under the state of car-following.
\end{abstract}

Keywords: driver assistance; driving tendency; pattern recognition ; rough set theory; feature extraction

\section{Introduction}

The driver's internal factors are important to impacting traffic safety in addition to vehicle-road-environment. The driver's internal factors include the driver's physiological and psychological characteristic. The physiological characteristic is the basis of the psychological characteristic and is reflected in the psychological characteristics. The differences of drivers' age, gender, driving experience and individuality result in the different psychological characteristics. And the different psychological characteristics are reflected as driving tendencies. The research of driving tendency recognition plays an important role in improving the applicability and accuracy of vehicle active safety systems (collision avoidance warning system, for example). Former researches focus mainly on driver characteristics and its impact on driving behavior ${ }^{[1-5]}$, deducing and forecasting of driving behavior from human, vehicle and environment factors ${ }^{[6-9]}$. At present, the researches of

Corresponding author: wangxiaoyuan@sdut.edu.cn. 
driving tendency focus mainly on driver psychological measurement and analysis of the influence on macroscopic traffic safety in a relatively static condition $^{[10][11]}$. Some researchers has introduced driver individual differences to vehicle active safety system. But there is still no detailed study on how to distinguish the driver's individual differences.

The driver's cognition and processing of the environment information (That is, Driver Behavior Characteristics) are influenced by physiological and psychological characteristics which are called driving tendency. And physiological and psychological characteristics can be gotten from driver's behavior ${ }^{[12-}$ 14]. Driving tendency recognition in driving-assistance system is within the domain of artificial psychology and emotion recognition ${ }^{[15][16]}$. So we can extract characteristic variables of driving tendency, and identify its type. The data of various driving tendency types (such as risk-taking, cautious and conservative)are obtained in the car-driving state through psychological questionnaire tests, observed experiments and real vehicle experiments. The feature extraction method based on rough set theory is used to extract eigenvectors with good ability to classify the type of driving tendency. The determinant of driving tendency is gotten through vehicle kinematics theory. The dynamic recognition method of driving tendency is put forward with model calibration and verification made use of real driving data. For simplicity, considering the intrusion of contact inspection to drivers, this paper focuses mainly on the driving tendency identification based on coordinate deduction of vehicle and road.

\section{The feature extraction of driving tendency under the state of car following}

Car following is the driving behavior that the driver can not overtake the front car at the state of non-free flow. And at this time the external factors of affecting driving state include vehicle characteristics, road conditions, traffic interference (such as speed limit signs), weather, mission priorities etc ${ }^{[17][18]}$. These factors have different influence on drivers' psychological emotional condition with different driving tendency. And the difference will be manifested in the form of drive operation and it will be reflected in the driving data ultimately. Therefore, the feature extraction method based on rough set theory in intelligent pattern recognition theory is used to analyze the macroscopical driving data and extract eigenvectors with good classification ability of driving tendency.

\subsection{Rough Set Theory}

\subsubsection{Rough Set Basic Theory ${ }^{[19][20][21]}$}

The Rough Set (RS) theory is put forward by Z. Pawlak from Polish, and it is a theory of researching the incomplete and uncertain knowledge. After 1990, rough set theory becomes a hot study in the field of artificial intelligence. And, it is successfully applied to data mining, feature selection, pattern recognition, fault detection, machine learning, decision analysis and other fields. Basic Theory of Rough Set is as follows:

In general, information systems (S)can be expressed as an ordered function:

$$
S=\{U, A, V, f\}
$$

Where, $U=\left\{x_{1}, x_{2}, \cdots, x_{n}\right\}$ is a set with a finite number of processing samples, that is all sample sets; $A$ is a set with limited number of properties, Attribute set $A$ can be further divided into two independent subsets, that $A=C \bigcup D, C \cap D=\varnothing . C$ is a condition attribute set reflecting the characteristics of the object, $D$ is a decision attribute reflecting the type of object; $V=\bigcup_{P \in A} V_{P}$ is a collection of attribute values, $V_{P}$ express attribute value range of property $P \in A$, that is the range of property $p ; f=U \times A \rightarrow V$ called information function is used to determine each object $x$ property values in $U$,that any $q \in A$ and $x_{i} \in U, f\left(x_{i}, q\right) \in V_{q}$.

For any subset of attributes $B \subseteq A$, If

$R(B)=\left\{\left(x_{i}, x_{j}\right) \in U^{2} \mid \forall a \in B, f\left(x_{i}, a\right)=f\left(x_{j}, a\right)\right\}$

Then, $R(B)$ is called indistinguishable relation, attribute subset $B$ divide all the sample set $U$ into a number of equivalence classes, and the equivalence class within the sample set is not distinguished.

For any subset of the sample $X \in U$, if

$$
B_{-}(X)=\{x \in U: B(x) \subseteq X\}
$$



if

Then $B_{-}(X)$ is the lower approximate limit of $X$,

$$
B^{-}(X)=\{x \in U: B(x) \cap X \neq \varnothing\}
$$

Then $B^{-}(X)$ is the $B$ lower approximate limit of $X$

$$
B N_{B}=B^{-}(X)-B_{-}(X)
$$

Then above formula is the $B$ boundary region of $X$. On this basis, $B$ positive and $X$ negative domain of $X$ are defined, and $\operatorname{pos}_{B}(X)$ and $n e g_{B}(X)$ are expressed respectively as followed:

$$
\begin{gathered}
\operatorname{pos}_{B}(X)=B_{-}(X) \\
\operatorname{neg}_{B}(X)=U-B_{-}(X)
\end{gathered}
$$

$\operatorname{pos}_{B}(X)$ express a subset constituted by the element that can be included in set $X$ in attributes $B, U$; $n e g_{B}(X)$ express a subset constituted by the element that can not be included in set $X$ in attributes $B, U$.

For a decision table, the role of rough set theory is reflected in the simplified decision table, including attribute reduction, that is Eliminate redundant attributes, object reduction, that is Eliminate redundant objects and value reduction (eliminate some redundant values of some attributes); rule extraction ,etc. Feature selection and extraction is essentially a problem of attribute reduction. For the family of equivalence relations $R$, exist $r \in R$, if

$$
\operatorname{ind}(R)=\operatorname{ind}(R-\{r\})
$$

Then $r$ can be omitted in $R$, otherwise $r$ can not be omitted in $R$, ind $(R)$ express that element in the set indiscernibility relation on $\mathrm{R}$. For a subset of attributes $P \subseteq R$, If there is $Q=P-r, Q \subseteq P$ ,make ind $(Q)=\operatorname{ind}(P)$, and $Q$ is the minimal subset, so $Q$ is called a reduction of $P$, denoted red $(P)$. The intersection of the simplified set $\operatorname{red}(P)$ is called the nuclear of $P$, denoted $\operatorname{core}(P)=\bigcap$ red $(P)$. Let $P$ and $S$ are two equivalence classes of $U, U \mid S=\left\{X_{1}, X_{2}, \cdots, X_{n}\right\}$, $P$ positive field of $S$ is:

$$
\operatorname{pos}_{p}(S)=\bigcup_{i=1}^{n} P_{-}\left(X_{i}\right)
$$

If there exists $r \in R$ and $r \in R$, called $r$ can be omitted in $P, P-\{r\}$ is the relative reduction of $S$.

The algorithms to searching reduction is called the data reduction algorithm, including heuristic reduction algorithm and the reduction algorithm based on discernibility matrix, etc.

\subsubsection{Discretization of continuous attributes based on minimum entropy ${ }^{[22][23]}$}

Before reducing decision table, it needs to be discrete processing. Traditional discrete processing methods include equidistant partition algorithm and equal frequency allocation algorithm. But these methods have ignored the category information of objects, and are easy to lose information. Discretization methods supervised such as minimum entropy method can overcome these problems to some extent. The Minimum entropy method select the class information entropy of candidate interval to take as the discrete threshold boundary. If it finds an interval boundary that can make entropy function be minimum, then this method can be used recursively in the two ranges produced after the border demarcation. If be given sample set $S$, properties $C$, and range boundaries $T, T$ divides $S$ into two intervals $S_{1}$ and $S_{2}$, the class information entropy of corresponding interval are $\operatorname{Ent}\left(S_{1}\right)$ and $\operatorname{Ent}\left(S_{2}\right)$, then $T$ produced the class information entropy can be expressed as:

$$
E(C, T, S)=\frac{S_{1}}{S} \operatorname{Ent}\left(S_{1}\right)+\frac{S_{2}}{S} \operatorname{Ent}\left(S_{2}\right)
$$

For a given attribute $C, E(C, T, S)$ is made as the smallest division point. $T$ is the best one in all candidate division point, denoted by $T_{\min }$, and makes it as the division point of the discretization, sample collection is divided into two subsets $S_{1}$ and $S_{2}$. We assume that $T_{1}$ and $T_{2}$ respective are the best division point in the $S_{1}$ and $S_{2}$, when we take the division point of $S_{1}$ and $S_{2}$ in the division point. They correspond to the class information entropy $E\left(C, T_{1}, S_{1}\right)$ and $E\left(C, T_{2}, S_{2}\right) \quad$ respectively. If $E\left(C, T_{1}, S_{1}\right)>E\left(C, T_{2}, S_{2}\right)$, then continue on the $S_{1}$ division, the other way round, continue on 
the $S_{2}$ division. We repeat the above method until the conditions are met:

$\operatorname{Gain}(C, T, S)<\frac{1 b(N-1)}{N}+\frac{\Delta(C, T, S)}{N}$

$\operatorname{Gain}(C, T, S)=\operatorname{Ent}(S)-\operatorname{Ent}(C, T, S)$

$\Delta(C, T, S)=1 b\left(3^{k}-2\right)-\left[\operatorname{Ent}(S)-k_{1} \operatorname{Ent}\left(S_{1}\right)-k_{2} \operatorname{Ent}\left(S_{2}\right)\right]$

$N$ is the number of sample in the set $S$ and $k_{1}$ and $k_{2}$ are the number of categories in the sets $S_{1}$ and $S_{2}$.

\subsubsection{Attribute reduction based on heuristic greedy algorithm ${ }^{[22]}$}

For an information system, the core may be empty set. That is, for the decision attribute, accurate classification considered only, each condition attribute can be reduced, so there are often multiple reduction paths for the attribute reduction of decision table. NP problems often occur with reduction because of the combinatorial explosion of the attribute. For the NP problem, the heuristic search method is taken to attribute reduction in general in the field of artificial intelligence. The greedy algorithm is a widely used heuristic reduction algorithm, and its structure is as followed:

Construct an information table $S^{*}=\left\langle U^{*}, A^{*}, V^{*}, f^{*}\right\rangle, U^{*}=\left\{\left(x_{i}, x_{j}\right) \in U^{*} U \mid d\left(x_{i}\right) \neq d\left(x_{j}\right)\right\}$. If $a\left(x_{i}\right) \neq a\left(x_{j}\right)$ in the attribute $\alpha$, then $a\left(x_{i}, x_{j}\right)=1$, otherwise $a\left(x_{i}, x_{j}\right)=0$.

Greedy algorithm specific steps:

Step One: a new information table $S^{*}$ is set up according to the original information table $S$; Step Two: the best of condition attributes $C U T=\varnothing$ is initialized; Step Three: select condition attribute with the largest number of 1 in columns of the information table to add to $C U T$. Get rid of the columns where condition attribute exist and all rows that value is 1 in this condition attribute. Step Four: if the information table in the element is not empty, then switch to Step two, otherwise stop the step. Then, CUT is the condition attribute set demanded.

\subsection{Driving tendency feature extraction based on rough set theory}

\subsubsection{Experimental Design}

- The taxi drivers are taken as the experimental subject, and 20 drivers of each type are selected though the psychological questionnaire tests. Divers that numbered from 1 to 20 belong to risktaking type, drivers that numbered from 21 to 40 belong to cautious type, and drivers that numbered from 41 to 60 belong to conservative type. There are 15 male drivers and 5 female drivers respectively in each type, their age are from 28 to 50 years old and driving experience are from 3 years to 23 years.

- Laboratory equipment:

(i) BTM300-905-200 laser range sensor: distance range is $1-150 \mathrm{~m}$, accuracy is $\pm 10-50 \mathrm{~cm}$, parameters frequency is $10-50 \mathrm{HZ}$.

(ii) GPS non-contact multi-function speedometer; CTM-8A non-contact multi-function speedometer.

(iii) Camera device:

(a) High definition cameras: It is used to photograph the driver hand operation, facial expression, the car environment, foot operation and road traffic conditions.

(b) Cameras monitoring software: MiniVcap monitoring system.

(c) Wide angle camera: It is used to photograph road traffic conditions.

- The experimental road chosen: The headway between the vehicle and the vehicle ahead is tested through driving the experimental vehicles which is fitted laser range sensors and camera device inside the vehicle along Zhangzhou Road. In the meantime, the wide angle camera and camera are set up in a building where the road traffic flow is easy to photograph. Real-time traffic information collecting video system is installed on the experimental road in cooperation with Zibo Traffic Police Department. The experimental route is as follow: Renmin Road - Xiba Road - Zhangzhou Road - Xiwu Road - Gongqingtuan Road - Shiji Road - Renmin Road. The length of experimental route is about $6000 \mathrm{~m}$; traffic state is non-free-flow; the weather and road condition were good.

- Experiment organization: The drivers are grouped by type of driving tendency, and there are 3 person that types are different per group. The driver of 
three types respectively drives along test sections in any lane from north door of Shandong University of Technology at Renmin Road. The experiment is carried out a week. And the experimental car is fitted with CTM-8A and SG299GPS Non-contact multi-function speedometer, laser measurement distance sensors and car camera device, and the road observation experiment is carried out at the same time.

- Data processing: The output data of CTM-8A and SG299GPS Non-Touching multi-function tachometer combine with the pictures of travel environment taken inside and outside of the cars. Through the comprehensive analysis, the driving data of high reliability are obtained. Driving data is organized by 0.5 second/one. Through the experimentally measured data, we can get the front and rear speed difference, the first vehicle speed, acceleration of the vehicle in front, front and rear acceleration variation.

\subsubsection{The feature extraction of driving tendency}

According to the previous research of personality characteristic, the driver's reaction time and the minimum stopping distance are often very different to the drivers with different characteristics ${ }^{[24-26]}$. Only realtime relative motion parameters of front and rear cars are extracted and analyzed considering the real-time and calculation efficiency of recognition model of driving tendency in the paper.

Establish decision table $S=\langle U, A, V, f\rangle, U$ is the set of all samples. Constitute traffic parameters attribute set of front and rear cars: $A=\left\{a_{1}, a_{2}, \cdots a_{10}\right\}=\left\{d, v_{1}, v_{2}, v_{r}, a_{1}, a_{2}, a_{r}, \Delta a_{1}, \Delta a_{2}, \Delta a_{r}\right\}$ ,where, $d$ is the distance between cars, $v_{1} v_{2}, v_{r}$ were the speed of target car, the speed of car in front and the relative speed (the speed difference of target car and the car in front). $a_{1}, \Delta a_{1}$ were the acceleration of target car and the variable quantity respectively, $a_{2}, \Delta a_{2}$ were acceleration of the car in front and the variable quantity respectively, $a_{r}, \Delta a_{r}$ were relative acceleration and variable quantity respectively; the category of driving tendency may be as a decision attribute set $D=\left\{d_{1}, d_{2}, d_{3}\right\}=\{$ adventurous type, cautious type, conservative type $\}$, in decision table, take number 0 as adventurous type, number 1as cautious type, number 2 as conservative type. The real driving data is used for feature extraction. Due to the larger data, The data need reduce by groups. Each group has about 150 real driving data, including 50 corresponding data in each type. Due to space limitation, only a set of data is listed. Decision table is established shown in table 1 (only part of the data are listed):

Table 1. Decision table

\begin{tabular}{|c|c|c|c|c|c|c|c|c|c|c|c|}
\hline No. & & & & Con & dition & attrib & utes & & & & Decision attribute \\
\hline$U$ & $a_{1}$ & $a_{2}$ & $a_{3}$ & $a_{4}$ & $a_{5}$ & $a_{6}$ & $a_{7}$ & $a_{8}$ & $a_{0}$ & $a_{10}$ & $D$ \\
\hline 1 & 15.70 & 13.03 & 13.30 & -0.27 & -3.04 & -2.95 & -0.09 & 3.13 & -3.05 & 0.08 & 0 \\
\hline 2 & 15.80 & 12.98 & 13.35 & -0.37 & 0.23 & 0.25 & -0.02 & 3.27 & 3.20 & 0.07 & 0 \\
\hline$\ldots$ & $\cdots$ & $\cdots$ & $\ldots$ & $\cdots$ & $\cdots$ & $\cdots$ & $\ldots$ & $\cdots$ & $\cdots$ & $\ldots$ & 0 \\
\hline 10 & 17.40 & 13.36 & 13.79 & -0.43 & -0.47 & -0.50 & 0.03 & 0.47 & 0.10 & 0.57 & 0 \\
\hline$\cdots$ & $\ldots$ & $\ldots$ & $\ldots$ & $\ldots$ & $\cdots$ & $\ldots$ & $\ldots$ & $\ldots$ & $\ldots$ & $\ldots$ & 0 \\
\hline 51 & 21.9 & 13.14 & 13.79 & -0.65 & 0.22 & 0.25 & -0.03 & 0.00 & 0.00 & 0.00 & 1 \\
\hline 52 & 22.0 & 13.2 & 13.84 & -0.64 & 0.23 & 0.25 & -0.02 & 0.00 & 0.00 & 0.00 & 1 \\
\hline$\ldots$ & $\ldots$ & $\ldots$ & $\ldots$ & $\ldots$ & $\ldots$ & $\ldots$ & $\ldots$ & $\ldots$ & $\ldots$ & $\ldots$ & 1 \\
\hline 60 & 22.8 & 13.66 & 13.83 & -0.17 & -0.25 & -0.25 & 0.00 & 0.00 & 0.00 & 0.00 & 1 \\
\hline ...... & $\ldots$ & $\ldots$ & $\ldots$ & $\ldots$ & $\ldots$ & $\ldots$ & $\ldots$ & $\ldots$ & $\ldots$ & $\ldots$ & 1 \\
\hline 101 & 22.9 & 12.31 & 12.85 & -0.54 & 0.32 & 0.35 & -0.03 & 0.04 & 0.05 & 0.01 & 2 \\
\hline 102 & 23.0 & 12.25 & 12.91 & -0.66 & 0.27 & 0.30 & -0.03 & 0.05 & 0.05 & 0.00 & 2 \\
\hline$\ldots$ & $\ldots$ & $\ldots$ & $\ldots$ & $\ldots$ & $\ldots$ & $\ldots$ & $\ldots$ & $\ldots$ & $\ldots$ & $\ldots$ & 2 \\
\hline 110 & 25.4 & 14.11 & 14.56 & -0.45 & -0.14 & -0.15 & 0.01 & 0.05 & 0.05 & 0.00 & 2 \\
\hline$\ldots$ & $\ldots$ & $\ldots$ & $\ldots$ & $\ldots$ & $\ldots$ & $\ldots$ & $\ldots$ & $\ldots$ & $\ldots$ & $\ldots$ & 2 \\
\hline 150 & 25.2 & 14.22 & 13.57 & 0.65 & 0.05 & -0.10 & 0.15 & 0.20 & 0.03 & 0.17 & 2 \\
\hline
\end{tabular}


Properties on above table are dispersed by use of the method of minimum entropy in 2.1.2. The decision table $S^{\prime}$ is shown in table 2 after eliminating redundant samples(samples that all properties discrete values are equal).
Decision table after discretization is executed attribute reduction according to greedy algorithm in 2.1.3. First, a new decision table $S^{*}$ (shown in Table 3) is constructed according to decision table $S^{*}$. Due to space limitations, only part of data is listed.

Table 2 Decision table $S^{\prime}$ after discretization

\begin{tabular}{cccccccccccc}
\hline$U$ & $a_{1}$ & $a_{2}$ & $a_{3}$ & $a_{4}$ & $a_{5}$ & $a_{6}$ & $a_{7}$ & $a_{8}$ & $a_{9}$ & $a_{10}$ & $D$ \\
\hline 1 & 2 & 4 & 2 & 4 & 2 & 1 & 1 & 5 & 2 & 2 & 0 \\
2 & 1 & 2 & 2 & 3 & 4 & 4 & 4 & 4 & 2 & 2 & 0 \\
4 & 2 & 2 & 2 & 3 & 4 & 3 & 5 & 4 & 2 & 1 & 0 \\
5 & 1 & 2 & 4 & 2 & 4 & 3 & 2 & 4 & 3 & 3 & 0 \\
7 & 2 & 3 & 1 & 3 & 4 & 1 & 2 & 3 & 4 & 3 & 0 \\
8 & 2 & 2 & 3 & 4 & 2 & 4 & 5 & 4 & 1 & 1 & 0 \\
9 & 1 & 2 & 4 & 4 & 4 & 2 & 2 & 3 & 3 & 3 & 0 \\
10 & 1 & 3 & 4 & 1 & 4 & 5 & 3 & 2 & 4 & 2 & 0 \\
$\ldots$ & $\ldots$ & $\ldots$ & $\ldots$ & $\ldots$ & $\ldots$ & $\ldots$ & $\ldots$ & $\ldots$ & $\ldots$ & $\ldots$ & 0 \\
14 & 2 & 3 & 5 & 3 & 2 & 2 & 2 & 3 & 4 & 3 & 0 \\
16 & 2 & 3 & 4 & 3 & 3 & 2 & 3 & 4 & 1 & 2 & 0 \\
19 & 1 & 2 & 5 & 4 & 2 & 2 & 3 & 3 & 3 & 3 & 0 \\
$\ldots$ & $\ldots$ & $\ldots$ & $\ldots$ & $\ldots$ & $\ldots$ & $\ldots$ & $\ldots$ & $\ldots$ & $\ldots$ & $\ldots$ & 0 \\
149 & 3 & 2 & 3 & 2 & 4 & 2 & 4 & 4 & 5 & 3 & 2 \\
\hline
\end{tabular}

Table 3 New decision table $S^{*}$

\begin{tabular}{cccccccccccc}
\hline$U^{*}$ & $a_{1}$ & $a_{2}$ & $a_{3}$ & $a_{4}$ & $a_{5}$ & $a_{6}$ & $a_{7}$ & $a_{8}$ & $a_{9}$ & $a_{10}$ & $\begin{array}{c}\text { number of } \\
\text { rows1 }\end{array}$ \\
\hline$(1,51)$ & 1 & 1 & 1 & 1 & 0 & 0 & 0 & 1 & 0 & 1 & 6 \\
$(1,52)$ & 0 & 1 & 0 & 1 & 1 & 0 & 1 & 0 & 0 & 0 & 4 \\
$(1,54)$ & 1 & 0 & 1 & 0 & 0 & 0 & 0 & 1 & 0 & 1 & 4 \\
$(1,55)$ & 1 & 1 & 1 & 1 & 1 & 1 & 0 & 0 & 0 & 1 & 7 \\
$(1,58)$ & 1 & 1 & 1 & 0 & 1 & 0 & 0 & 0 & 0 & 0 & 4 \\
$(1,59)$ & 1 & 1 & 1 & 1 & 0 & 0 & 1 & 0 & 0 & 0 & 5 \\
$\ldots$ & $\ldots$ & $\ldots$ & $\ldots$ & $\ldots$ & $\ldots$ & $\ldots$ & $\ldots$ & $\ldots$ & $\ldots$ & $\ldots$ & $\ldots$ \\
$(98,149)$ & 0 & 0 & 0 & 0 & 1 & 1 & 1 & 0 & 0 & 0 & 3 \\
$(99,149)$ & 1 & 1 & 1 & 0 & 1 & 0 & 1 & 0 & 0 & 1 & 6 \\
number of columns1 & 1312 & 1050 & 785 & 820 & 750 & 470 & 210 & 56 & 82 & 74 & \\
\hline
\end{tabular}

Select the attribute $a_{1}$ with the largest number of 1 in all columns of the decision table $S^{*}$ to add to $C U T$.
Get rid of the columns where the breakpoint exist and all rows that value is 1 on this breakpoint. The results are shown in Table 4. 
Table 4 Intermediate results table

\begin{tabular}{ccccccccccccc}
\hline$U^{*}$ & $a_{1}$ & $a_{2}$ & $a_{3}$ & $a_{4}$ & $a_{5}$ & $a_{6}$ & $a_{7}$ & $a_{8}$ & $a_{9}$ & $a_{10}$ & number of rows1 \\
\hline$(1,51)$ & $*$ & $*$ & $*$ & $*$ & $*$ & $*$ & $*$ & $*$ & $*$ & $*$ & & $*$ \\
$(1,52)$ & $*$ & 1 & 0 & 1 & 1 & 0 & 1 & 0 & 0 & 0 & 4 \\
$(1,54)$ & $*$ & $*$ & $*$ & $*$ & $*$ & $*$ & $*$ & $*$ & $*$ & $*$ & & $*$ \\
$(1,55)$ & $*$ & $*$ & $*$ & $*$ & $*$ & $*$ & $*$ & $*$ & $*$ & $*$ & & $*$ \\
$(1,58)$ & $*$ & $*$ & $*$ & $*$ & $*$ & $*$ & $*$ & $*$ & $*$ & $*$ & & $*$ \\
$(1,59)$ & $*$ & $*$ & $*$ & $*$ & $*$ & $*$ & $*$ & $*$ & $*$ & $*$ & & $*$ \\
$\ldots$ & $\ldots$ & $\ldots$ & $\ldots$ & $\ldots$ & $\ldots$ & $\ldots$ & $\ldots$ & $\ldots$ & $\ldots$ & $\ldots$ & & $\ldots$ \\
$(98,149)$ & $*$ & 0 & 0 & 0 & 1 & 1 & 1 & 0 & 0 & 0 & & 3 \\
$(99,149)$ & $*$ & $*$ & $*$ & $*$ & $*$ & $*$ & $*$ & $*$ & $*$ & $*$ & & $*$ \\
\hline
\end{tabular}

If elements in decision table $S^{*}$ are not empty, then repeat above reduction procedure. Finally there are condition attributes $a_{1}, a_{2}, a_{4}, a_{5}$ and $a_{7}$ in $C U T$. Attribute reduction ultimately results are shown in Table 5.

Table 5 Decision table after Attribute reduction

\begin{tabular}{ccccccc}
\hline$U$ & $a_{1}$ & $a_{2}$ & $a_{4}$ & $a_{5}$ & $a_{7}$ & $D$ \\
\hline 2 & 2 & 2 & 3 & 4 & 4 & 0 \\
9 & 1 & 2 & 4 & 4 & 2 & 0 \\
14 & 2 & 3 & 3 & 2 & 2 & 0 \\
24 & 3 & 4 & 5 & 2 & 4 & 0 \\
27 & 1 & 2 & 3 & 4 & 5 & 0 \\
30 & 1 & 3 & 2 & 3 & 4 & 0 \\
\hline
\end{tabular}

Table 5 Decision table after Attribute reduction(Continued)

\begin{tabular}{ccccccc}
\hline$U$ & $a_{1}$ & $a_{2}$ & $a_{4}$ & $a_{5}$ & $a_{7}$ & $D$ \\
\hline$\ldots$ & $\ldots$ & $\ldots$ & $\ldots$ & $\ldots$ & $\ldots$ & $\ldots$ \\
135 & 3 & 3 & 2 & 3 & 1 & 2 \\
138 & 4 & 3 & 2 & 4 & 3 & 2 \\
143 & 2 & 3 & 2 & 2 & 4 & 2 \\
146 & 4 & 1 & 2 & 3 & 5 & 2 \\
149 & 4 & 3 & 5 & 3 & 4 & 2 \\
\hline
\end{tabular}

According to above reduction process, other driving data sets can be carried out attribute reduction. Then, all condition attributes sets $C U T$ after reduction are taken intersection $\bigcap C U T$. $\bigcap C U T$ contains attributes $a_{1}, a_{2}, a_{4}, a_{5}$ and $a_{7}$, corresponding to traffic parameters $d, v_{1}, v_{r}, a_{1}$ and $a_{r}$. That is, through the feature extraction process of attribute reduction, we can get the variables with better classification capability in the whole set of traffic parameters, such as vehicle distance, the target vehicle speed, relative speed, the target vehicle acceleration and relative acceleration. According to this, we can establish the dynamic recognition model to identify driving tendency under the state of car following.

\section{Establishment of driving tendency recognition model}

\subsection{Determined indicators}

\subsubsection{Spacing conditions}

The safety distance between the car and the car in front on the same lane is taken as warning distance in the current research of vehicle collision avoidance warning system. And it is the minimum headway when the car in front stop urgently, the rear car can also stop and without rear-end accidents ${ }^{[13,27-30]}$.. Assume the driving distance is $d_{s}$, the safety distance can be expressed as followed:

$$
d_{s}=\frac{v_{1}^{2}}{2 a_{f}}-\frac{v_{2}^{2}}{2 a_{l}}+v_{1} t_{\text {reaction }}+d_{0}
$$

Where $v_{1}, a_{f}$ is the target front car speed and the maximum braking deceleration, $v_{2}, a_{l}$ is the target behind car speed and the maximum braking deceleration, $a_{l}=a_{f}=\varphi g$, where $\varphi$ is the road friction coefficient, $g$ is the acceleration of gravity, $t_{\text {reaction }}$ is the target car's driver operating response time, including the time from driver sensing the front signal and generating the deceleration intent to the time of vehicle brake system start role, $d_{0}$ is the minimum parking space.

However, the safe driving distance varies according to the road conditions, traffic conditions, environmental conditions and the difference of drivers' characteristics 
under real driving. And it mainly depends on the driver's own subjective feelings and desires. Due to the difference of the driving tendency, drivers' feeling of safe driving distance and requirements of driving efficiency are different. For example, the older drivers tend to be more conservative compared to the young drivers while driving, and the safety distance is often greater. Refer to formula (14), there are deviations between subjectively determine safe distance (Psychological safe distance) and reality safe distance to drivers with different driving tendency, and the deviations can be reflected in the difference of reaction time and minimum parking space. The driver types can be divided into conservative type, cautious type and risk-taking type. If the impact factor of the driving tendency to drivers is $k$, then the driver's psychological safety distance can be expressed as follows:

$$
d_{p}=\frac{v_{1}^{2}}{2 a_{f}}-\frac{v_{2}^{2}}{2 a_{l}}+k \cdot v_{1} t_{\mathrm{r}}+k \cdot d_{0}
$$

The meanings of variables of above formula are the same as formula (14).

Because of drivers' individual differences, the value of the driver reaction time and minimum parking space are different in the above formula. In this paper, $t_{\mathrm{r}}$ and $d_{0}$ are taken $1.25 \mathrm{~s}$ and $2 \mathrm{~m}$ according to reference[18][20], then $k \cdot t_{r}$ and $k \cdot d_{0}$ represent reaction time and the minimum stopping distance respectively to drivers with different driving tendency. $d_{p 1}, d_{p 2}, d_{p 3}$ represent psychological safety space of conservative type, cautious type and risk-taking type.

When the car is moving, the rear car driver will make sure the distance between the two cars not less than the psychological safety distance in order to ensure traffic safety. When the driving distance reaches psychological safety distance, the rear car is under stable state of car-following relative to the car in front, and $k$,value in formula (15) , can be determined by vehicular gap and relevant data of each type drivers under stable car- following. $d_{p 1}, d_{p 2}, d_{p 3}$ can be calculated at any time according to $k_{1}, k_{2}, k_{3}$, then the driving type can be judged by $d-d_{p}$, where $d$ is the distance between the two cars at that time.

\subsubsection{Movement State}

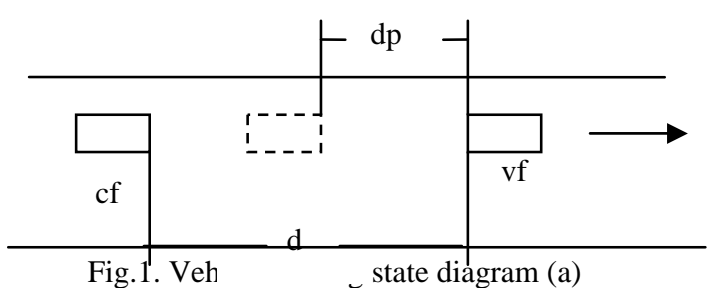

Note: dp: Psychological safety distance; cf: Car Following; d: Driving distance; vf: vehicle in front.

If $d-d_{p}>0$, when $d_{p}$ takes any value of $d_{p 1}, d_{p 2}$ and $d_{p 3}$, it is not enough to judge the driving type by $d-d_{p}$. And it needs to determine whether the driver has reached the psychological safety distance under the state of car-following. This situation has two type of car running status:

- When the vehicle is moving, if the driving distance reaches the rear car driver's psychological safety distance at some time, then the relative velocity is as follows:

$$
v_{r}=v_{1}-v_{2}=0
$$

- If the driver thinks that driving distance is too small, unable to meet his own safe driving condition at some time, the driver will slow down to widen the driving distance under the state of carfollowing. Through analyzing the movement relationship at this time, following formula can be gotten:

$$
d_{n}>d_{n-1} \text { and } a_{1}<0
$$

$d_{n}, d_{n-1}$ are the driving distance at the moment and the last time moment respectively, $a_{1}$ is the following car acceleration. If $\Delta s_{1}, \Delta s_{2}$ represent respectively the distance of the following car and the front car in a scan interval, then the above equation is equivalent to:

$$
\Delta s_{1}<\Delta s_{2} \text { and } a_{1}<0
$$

If

$$
\Delta s_{1}=v_{1} \Delta t+\frac{1}{2} a_{1} \Delta t^{2}
$$




$$
\Delta s_{2}=v_{2} \Delta t+\frac{1}{2} a_{2} \Delta t^{2}
$$

Then in a scan interval:

$$
\Delta s_{1}-\Delta s_{2}=\left(v_{1}-v_{2}\right)+\frac{1}{2}\left(a_{1}-a_{2}\right)=v_{r}+\frac{1}{2} a_{r} \Delta t
$$

$\Delta t$ is the scan interval, $\mathrm{D}$ is the relative acceleration. Make above formula is less than 0 , then the requirement that meet the conditions of $\Delta s_{1}<\Delta s_{2}$ and $a_{1}<0$ is as follows:

$$
\left\{\begin{array}{c}
a_{1}<0, a_{r}<0, v_{r}<0 \\
o r \\
a_{1}<0, a_{r}<0,0<2 v_{r}<\left|a_{r}\right| \Delta t
\end{array}\right.
$$

Therefore, driving tendency type can be determined by formula (16), (22) and $d-d_{p}$.

\subsection{Establishment of the recognition model}

Step1. Take $\varphi=0.8$ as asphalt (dry) road average friction coefficient, so $a_{l}=a_{f}=\varphi g=-7.84\left(\mathrm{~m} / \mathrm{s}^{2}\right)$. Vehicular gap and relevant data of each type drivers under stable car-following are filled in formula (15), then three scales of $k$ can be obtained: $k_{1}, k_{2}$ and $k_{3}$.The possible psychological security distance $\left(d_{p 1}, d_{p 2}, d_{p 3}\right)$ can be calculated by $k_{1}, k_{2}, k_{3}$ and $\mathrm{t} v_{1}, v_{2}$ of the target vehicle. Let $d_{p \max 1}$ and $d_{p \min 1}$ as $d_{p 1}$ 's upper and lower limits, $d_{p \max 2}, d_{p \min 2}$ as $d_{p 2}$ 's upper and lower limits, $d_{p \max 3}, d_{p \min 3}$ as $d_{p 3}$ 's upper and lower limits.

Step2. The vehicle will be affected by the vehicle in front when the headway is less than 70 meters, that is, the vehicle is under the state of car-following ${ }^{[29]}$.

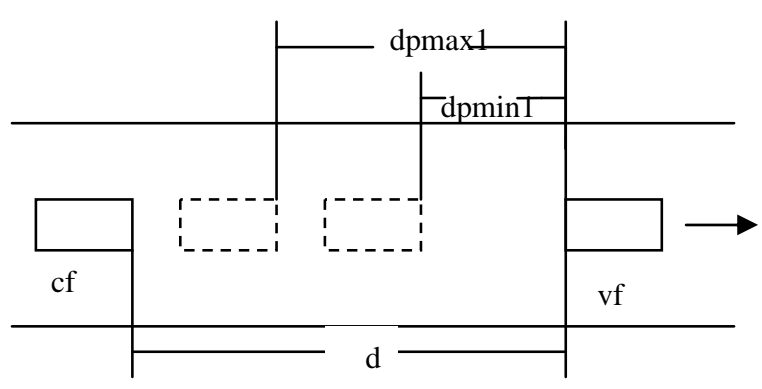

Fig.2. Vehicle driving state diagram (b)

Note: dp: Psychological safety distance; cf: Car Following; d: Driving distance; vf: vehicle in front. Driving distance $d_{p \max 1}>d \geq d_{p \min 1}$, if $v_{r}=0$ Or

$$
\left\{\begin{array}{l}
a_{1}<0, a_{r}<0, v_{r}<0 \\
o r \\
a_{1}<0, a_{r}<0,0<2 v_{r}<\left|a_{r}\right|
\end{array}\right.
$$

Then the driver belongs to conservative type;

If the above conditions are not met, then the driver can be defined as conservative type temporarily when $d>d_{p \max 1}$ and the driver can be defined as cautious type temporarily when $d_{p \min 1} \leq d<d_{p \max 1}$, and so on.

Step3.

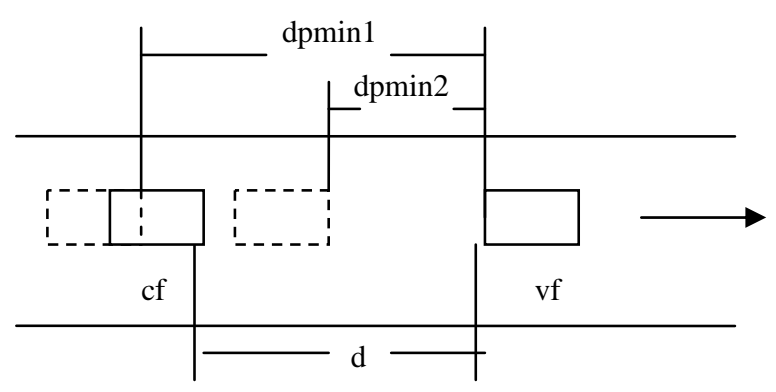

Fig.3. Vehicle driving state diagram (c)

Note: dp: Psychological safety distance; cf: Car Following; d: Driving distance; vf: vehicle in front. If $d_{p \min 2} \leq d<d_{p \min 1}$, and $v_{r}=0$ Or

$$
\left\{\begin{array}{c}
a_{1}<0, a_{r}<0, v_{r}<0 \\
o r \\
a_{1}<0, a_{r}<0,0<2 v_{r}<\left|a_{r}\right|
\end{array} .\right.
$$


Then the driver belongs to cautious type; if the conditions are not met, then the driver can be defined as risk type temporarily.

Step4.

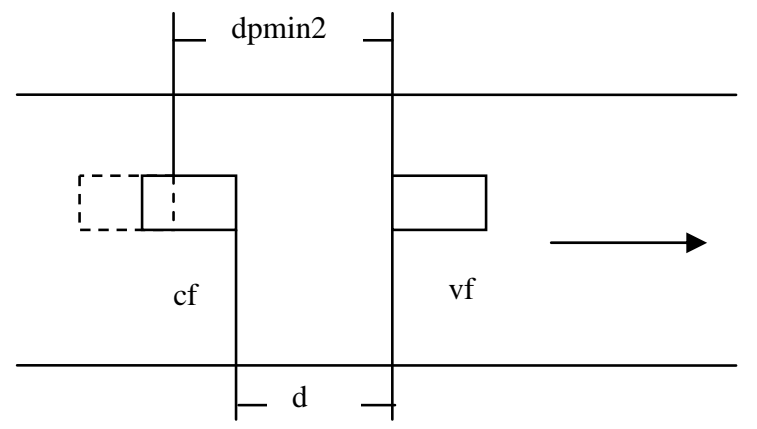

Fig.4. Vehicle driving state diagram (d)

\section{Calibration of recognition model}

There are 60 sets experimental data in total obtained from the real vehicle experiment in the feature extraction research. 16 groups selected from each type drivers data, 48 groups in total, are used for model calibration, and the other 12 groups are used for model validation. Due to space limitations, only part of the data that used for model calibration are listed in Table 6-8.

The data of the time met $v_{r}=0$ is extracted from the experimental data, then the value of $k$ can be demarcated. And the impact factors of driving tendency corresponding to each type can be obtained: $k_{1}=[1.067,1.212] \quad, \quad k_{2}=[0.938,1.065]$ $k_{3}=[0.815,0.937]$.

Note: meaning of $d p, c f, d$ and $v f$ is the same as above. If $d<d_{p \min 2}$, then the drive belongs to $\mathrm{r}$ is risk type.

Table 6. Risk-based driver part of the experimental data

\begin{tabular}{|c|c|c|c|c|c|c|}
\hline $\begin{array}{l}\text { Time } \\
(\mathrm{s})\end{array}$ & $\begin{array}{l}\text { Target vehicle } \\
\text { acceleration } \\
\left(\mathrm{m} / \mathrm{s}^{2}\right)\end{array}$ & $\begin{array}{c}\text { Relative } \\
\text { acceleration } \\
\left(\mathrm{m} / \mathrm{s}^{2}\right)\end{array}$ & $\begin{array}{c}\text { Vehicle } \\
\text { spacing (m) }\end{array}$ & $\begin{array}{c}\text { Target } \\
\text { vehicle } \\
\text { speed }(\mathrm{m} / \mathrm{s})\end{array}$ & $\begin{array}{l}\text { Vehicle in front } \\
\text { speed }(\mathrm{m} / \mathrm{s})\end{array}$ & $\begin{array}{c}\text { Relative } \\
\text { velocity } \\
(\mathrm{m} / \mathrm{s})\end{array}$ \\
\hline$\ldots \ldots$ & $\ldots \ldots$ & ...... & $\ldots \ldots$ & $\ldots \ldots$ & $\ldots \ldots$ & $\ldots \ldots$ \\
\hline 141.00 & -1.26 & 0.04 & 17.50 & 13.41 & 13.74 & -0.33 \\
\hline 141.50 & -1.44 & 0.06 & 15.90 & 12.97 & 13.44 & -0.47 \\
\hline 142.00 & 0.32 & -0.03 & 16.00 & 12.98 & 13.51 & -0.53 \\
\hline 142.50 & 0.63 & -0.02 & 17.60 & 13.51 & 13.64 & -0.13 \\
\hline$\ldots \ldots$ & ...... & $\ldots \ldots$ & $\ldots \ldots$ & $\ldots \ldots$ & $\ldots \ldots$ & $\ldots \ldots$ \\
\hline 153.50 & 0.14 & -0.01 & 17.30 & 13.32 & 13.81 & -0.49 \\
\hline 154.00 & 0.27 & -0.03 & 17.00 & 13.27 & 13.87 & -0.60 \\
\hline 154.50 & -0.05 & 0.00 & 17.20 & 13.30 & 13.86 & -0.56 \\
\hline$\ldots \ldots$ & ...... & ...... & ...... & ...... & ...... & $\ldots \ldots$ \\
\hline
\end{tabular}


Table 7. Cautious type driver part of the experimental data

\begin{tabular}{ccccccc}
\hline Time $(\mathrm{s})$ & $\begin{array}{c}\text { Target vehicle } \\
\text { acceleration } \\
\left(\mathrm{m} / \mathrm{s}^{2}\right)\end{array}$ & $\begin{array}{c}\text { Relative } \\
\text { acceleration } \\
\left(\mathrm{m} / \mathrm{s}^{2}\right)\end{array}$ & $\begin{array}{c}\text { Vehicle } \\
\text { spacing } \\
(\mathrm{m})\end{array}$ & $\begin{array}{c}\text { Target } \\
\text { vehicle } \\
\text { speed }(\mathrm{m} / \mathrm{s})\end{array}$ & $\begin{array}{c}\text { Vehicle in } \\
\text { front speed } \\
(\mathrm{m} / \mathrm{s})\end{array}$ & $\begin{array}{c}\text { Relative } \\
\text { velocity } \\
(\mathrm{m} / \mathrm{s})\end{array}$ \\
\hline$\ldots \ldots$ & $\ldots \ldots$ & $\ldots \ldots$ & $\ldots \ldots$ & $\ldots \ldots$ & $\ldots \ldots$ & $\ldots \ldots$ \\
118.00 & 0.35 & -0.05 & 20.60 & 12.60 & 13.33 & -0.73 \\
118.50 & 0.27 & -0.03 & 20.70 & 12.66 & 13.39 & -0.73 \\
119.00 & 0.18 & -0.02 & 20.90 & 12.71 & 13.43 & -0.72 \\
$\ldots \ldots$ & $\ldots \ldots$ & $\ldots \ldots$ & $\ldots \ldots$ & $\ldots \ldots$. & $\ldots \ldots$ & $\ldots \ldots$ \\
129.50 & -0.26 & -0.01 & 22.70 & 13.91 & 13.58 & 0.33 \\
130.00 & -0.27 & -0.02 & 22.60 & 13.96 & 13.53 & 0.43 \\
130.50 & -0.27 & -0.02 & 22.50 & 14.01 & 13.48 & 0.53 \\
\hline
\end{tabular}

Table 8. Conservative type driver part of the experimental data

\begin{tabular}{|c|c|c|c|c|c|c|}
\hline Time (s) & $\begin{array}{c}\text { Target vehicle } \\
\text { acceleration } \\
\left(\mathrm{m} / \mathrm{s}^{2}\right)\end{array}$ & $\begin{array}{c}\text { Relative } \\
\text { accelerati } \\
\text { on } \\
\left(\mathrm{m} / \mathrm{s}^{2}\right)\end{array}$ & $\begin{array}{l}\text { Vehicle } \\
\text { spacing } \\
\text { (m) }\end{array}$ & $\begin{array}{c}\text { Target } \\
\text { vehicle speed } \\
(\mathrm{m} / \mathrm{s})\end{array}$ & $\begin{array}{l}\text { Vehicle in } \\
\text { front speed } \\
\qquad(\mathrm{m} / \mathrm{s})\end{array}$ & $\begin{array}{c}\text { Relative } \\
\text { velocity }(\mathrm{m} / \mathrm{s})\end{array}$ \\
\hline$\ldots \ldots$ & ...... & $\ldots \ldots$ & $\ldots \ldots$ & $\ldots \ldots$ & $\ldots \ldots$ & $\ldots \ldots$ \\
\hline 177.50 & 0.28 & 0.53 & 23.30 & 12.97 & 12.18 & 0.79 \\
\hline 178.00 & 0.06 & 0.11 & 23.20 & 12.91 & 12.17 & 0.74 \\
\hline 178.50 & 0.17 & 0.02 & 23.00 & 12.86 & 12.20 & 0.66 \\
\hline$\ldots \ldots$ & $\cdots \cdots$ & $\ldots \ldots$ & $\ldots \ldots$ & $\cdots \cdots$ & $\cdots \cdots$ & $\cdots \cdots$ \\
\hline 189.00 & 0.14 & 0.29 & 25.60 & 14.21 & 14.50 & -0.29 \\
\hline 189.50 & 0.20 & 0.40 & 25.60 & 14.26 & 14.46 & -0.20 \\
\hline 190.00 & 0.20 & 0.40 & 25.70 & 14.31 & 14.42 & -0.11 \\
\hline
\end{tabular}

\section{Verification of driving tendency recognition model}

The remaining 12 groups experimental data are used for model (established in 3.2) verification. $R$ represents tendency type gotten by calculating, and $R=0,1,2$ represent risk-risking type, cautious type and conservative type respectively. Part of the data (from NO18 driver experimental data) and the results are shown in Table 9:

Table 9. Model validation Part of the data

\begin{tabular}{|c|c|c|c|c|c|c|c|c|c|c|}
\hline \multirow{2}{*}{$\begin{array}{l}\text { Time } \\
\text { (s) }\end{array}$} & \multirow{2}{*}{$\begin{array}{l}a_{1} \\
\left(\mathrm{~m} / \mathrm{s}^{2}\right)\end{array}$} & \multirow{2}{*}{$\begin{array}{l}a_{r} \\
\left(\mathrm{~m} / \mathrm{s}^{2}\right)\end{array}$} & \multirow{2}{*}{$d(\mathrm{~m})$} & \multirow{2}{*}{$\begin{array}{l}v_{1} \\
(\mathrm{~m} / \mathrm{s})\end{array}$} & \multirow{2}{*}{$\begin{array}{l}v_{2} \\
(\mathrm{~m} / \mathrm{s})\end{array}$} & \multirow{2}{*}{$\begin{array}{l}v_{r} \\
(\mathrm{~m} / \mathrm{s})\end{array}$} & \multicolumn{3}{|c|}{$d_{p}$} & \multirow[t]{2}{*}{$R$} \\
\hline & & & & & & & $d_{p 1}$ & $d_{p 2}$ & $d_{p 3}$ & \\
\hline$\ldots \ldots$ & $\ldots \ldots$ & $\ldots \ldots$ & $\ldots \ldots$ & $\ldots \ldots$ & $\ldots \ldots$ & $\ldots \ldots$ & $\ldots \ldots$ & $\ldots \ldots$ & $\ldots \ldots$ & ... \\
\hline 105.00 & 0.14 & -0.01 & 19.10 & 14.18 & 14.64 & -0.46 & $21.744,24.604$ & $19.199,21.704$ & $17.773,19.953$ & 0 \\
\hline 105.50 & 0.14 & -0.01 & 19.20 & 14.17 & 14.67 & -0.50 & $21.811,24.670$ & $19.269,21.772$ & $17.844,19.916$ & 0 \\
\hline$\ldots \ldots$ & $\ldots \ldots$ & $\ldots \ldots$ & $\ldots \ldots$ & $\ldots \ldots$ & $\ldots \ldots$ & $\ldots \ldots$ & $\ldots \ldots$ & $\ldots \ldots$ & $\ldots \ldots$ & .. \\
\hline 122.00 & -0.27 & -0.02 & 17.00 & 14.08 & 13.41 & 0.67 & $19.663,22.505$ & $17.134,19.624$ & $14.724,17.115$ & 0 \\
\hline 122.50 & -0.27 & -0.02 & 16.90 & 14.02 & 13.36 & 0.66 & $19.610,22.441$ & $17.091,19.571$ & $14.690,17.072$ & 0 \\
\hline$\ldots \cdots$ & $\ldots \ldots$ & $\ldots \ldots$ & $\ldots \ldots$ & $\ldots \ldots$ & $\ldots \ldots$ & $\ldots \ldots$ & $\ldots \ldots$ & $\ldots \ldots$ & $\ldots \ldots$ & $\ldots$ \\
\hline 128.00 & -0.27 & -0.02 & 15.60 & 13.37 & 12.81 & 0.56 & $18.704,21.418$ & $16.291,18.667$ & $13.989,16.272$ & 0 \\
\hline 128.50 & -0.33 & -0.03 & 15.40 & 13.31 & 12.75 & 0.56 & $18.492,21.194$ & $16.088,18.455$ & $13.795,16.069$ & 0 \\
\hline
\end{tabular}


Recognition results at some time can be obtained through recognition model in 3.2 using the data in above table. And the final recognition result shows that the driver belongs to risk-taking type which agrees well with the psychological questionnaire tests results. According to the recognition ideas of the model established, when the driver is accelerating towards front car or decelerating under car-following at larger change speed, the driving distance is greater and the accuracy of the model real-time recognition will be slightly lower. But with the driving distance approaching the psychological safety distance, the model can identify still the type of driving tendency accurately. Data listed in Table 9 are the date when the driver follows the front car in relatively stable conditions, the driver achieves psychological security space basically, and adjusts his speed in order to remain the driving state of psychological security distance at this time. From the recognition results, the judgment of recognition model of driving tendency type is accurate relatively. The final validation results of the 12 sets dada are shown in Table 10, and the percentages of accuracy is the percentages that the driver belongs to the corresponding driving tendency type. Results show that the recognition model established can realize real-time recognition of the type of driving tendency under the state of car-following.

Table 10. Verification Results

\begin{tabular}{cccccc}
\hline $\begin{array}{c}\text { Driver } \\
\text { Number }\end{array}$ & $\begin{array}{c}\text { Model Verification } \\
\text { Results (Accuracy) }\end{array}$ & $\begin{array}{c}\text { Psychological test } \\
\text { results }\end{array}$ & $\begin{array}{c}\text { Driver } \\
\text { Number }\end{array}$ & $\begin{array}{c}\text { Model Verification } \\
\text { Results(Accuracy) }\end{array}$ & $\begin{array}{c}\text { Psychological test } \\
\text { results }\end{array}$ \\
\hline 57 & Conservative(96.0\%) & 76 (Conservative) & 17 & Risk type (91.9\%) & 46(Risk type) \\
37 & Cautious (93.6\%) & 50(Cautious) & 20 & Risk type (90.8\%) & 48(Risk type) \\
58 & Conservative(94.0\%) & 72 (Conservative) & 18 & Risk type (94.1\%) & 43(Risk type) \\
59 & Conservative(95.3\%) & 73 (Conservative & 40 & Cautious (91.4\%) & 54 (Cautious) \\
38 & Cautious (89.6\%) & 53(Cautious) & 60 & Conservative(95.0\%) & 77(Conservative) \\
39 & Cautious (88.9\%) & 65(Cautious) & 19 & Risk type (95.5\%) & 47(Risk type) \\
\hline
\end{tabular}

\section{Conclusions}

Driving tendency is the comprehensive embodiment of driver's physiological and psychological characteristics. It reflects driver's psychological condition during the process of driving. In this paper, the feature extraction method based on rough set theory is used to extract eigenvectors with good ability to classify the type of driving tendency. Dynamic recognition model of driving tendency is put forward with calibration and verification making use of real data. Results show that the recognition method is feasible, and can realize realtime recognition of the driver tendency under the state of car-following. It can provide theoretical basis for the realization of automobile active safety system personalized.

\section{Acknowledgements}

This paper is sponsored by Country Natural Science Foundation Research Projects of China(61074140, 60974094)

\section{References}

1. X.Y.Wang, Development of an Integrated Cognitive Microscopic Traffic Simulation Model, J. Computer simulation.22(11)(2005) 233-236.

2. S. H. Hamdar, H. S. Mahmassani (eds.),. Aggressiveness Propensity Index for Driving Behavior at Signalized Intersections(Accident Analysis and Prevention,2008)pp.315-326.

3. Y.Q.Fen,C.Q.Fang(eds.),The clustering analysis of driver characteristics evaluation index. Communications(Science and Technology Heilongjiang,2007),pp.161-163.

4. X.M.CHEN,L.W.GAO(eds.),Research on Subjective Judgment of Driving Tenseness and Control of Vehicle Motion, J. Journal of Highway and Transportation Research and Development. 24(8)(2007) 144-148.

5. X.Y.Wang, L.Wang(eds.), Study on the Cooperative Simulation Algorithm of the Driving Behavior Based on Multi-information Fusion, J. Computer Engineering and Applications. 42(24) (2006) 195-198.

6. C.Z.Wu, X.F.Ma(eds.),Car Following Model Based on Drivers' Reaction Time, J. Journal of Wuhan University 
of Technology(Transportation Science \& Engineering).31(4)(2007)630-632.

7. B.Cheng, T. Tetsuo(eds.),Characteristics of driver behavior in car-following, J. Review of Automotive Engineering. 26(2)(2005)191-199.

8. Y.H.WANG, J.SONG(eds.),Study on Inference of Driver's Intentions Based on Fuzzy Reasoning , J. Journal of Highway and Transportation Research and Development. 22(12)(2005) 113-118.

9. C.Y. Fang, C.S. Fuh(eds.), An automatic road sign recognition system based on a computational model of human recognition processing, J. Computer Vision and Image Understanding. 96(2)(2004) 237-268.

10. H.L.Wang, Z.G.Liu(eds.),Internal Factors analysis of influencing vehicle driver driving safety(Automobile Safety,2002)pp.33-35.

11. R.P.Qian, Z.G.Zhang. Driver accident Tendentiousness psychological research and the countermeasures, J. Auto Application.10(2006).

12. J.Q.WANG, R.J.CHI(eds.). Study on Forward Collision Warning-avoidance Algorithm Based on Driver Characteristics Adaptation, J. Journal of Highway and Transportation Research and Development. 26(s1)(2009) 8-12.

13. Y.Gen, A. J. Richardson(eds.),Trust and Driver Expectation for Forward Collision Warning System, J. Applied Ergonomics. 27(2006)577-586.

14. Z.F.Shao, Cognitive Psychology-Theory, (Experiment and Application, ShangHai, Shanghai EducationPress,2006).

15. Z.L.Wang, Artificial Psychology(Beijing,China Machine Press,2007).

16. Z.L.Wang, C.S.Zhu(eds.) Artificial emotion(Beijing,China Machine Press,2009).

17. L. Daniel. Traffic flow theory(Beijing, China Communications Press,1983).

18. X.Y.WANG, L.XING(eds.),Driver's desired speed based on decision tree model, J. Journal of Computer Applications. 29(z2)(2009) 318-321.

19. J.H.Xiao. Intelligent Pattern Recognition (GuangZhou, South China University of Technology Press,2005).

20. W.X.Zhang. Rough set theory and methods(Beijing, Science Press,2001).

21. N.Li, C.W.Qu(eds.), Radar emitter signal recognition based on rough set, J. Aerospace Electronic Warfare. 26(4)(2010)8-10.

22. Q.Y.Zhang, M.Li. Rough set theory and the applications in the power sector( BeiJing, China Machine Press,2009).

23. X.Que, X.G.Hu(eds.), The research on continuous attributes discretization method based interval information entropy(Computer technology and application development,2006),PP.236-239.

24. W.C.Zhang. Motor vehicle road traffic safety questions and answers (BeiJing: China Communications Press, 1998).
25. F.Zhang, H.Y.Xuan(eds.), Lane Changing Model Based on Finite State Automaton, J. China Journal of Highway and Transport. 21(3)(2008) 97-100.

26. J.Liu, J.Rong(eds.), Theoretical Model of Highway Capacity Based on Variable Deceleration Time, J. Journal of Wuhan University of Technology(Transportation Science \& Engineering).29(6)(2005)891-894.

27. M.Nakaoka, P.Raksincharoensak(eds.), Study on Forward Collision Warming System Adapted to Driver Characteristics and Road Environment(International Conference on Control, Automation and Systems 2008, in COEX. Seoul,2008)pp.2890-2895.

28. W.Zhou, Analysis of Distance Headway, J. Journal of Southeast University.19(4)(2003) 379-381.

29. Z.S.Yu. Automobile Theory(BeiJing, China Machine Press,1996).

30. W.H. Wang, Y. Mao(eds.)Driver's various information process and multi-ruled decision-making mechanism: a fundamental of intelligent driving shaping model, J. International Journal of Computational Intelligence Systems. 4(3)(2011) 297-305. 